\begin{abstract}
Iranica
Abstracta Iranica Revue bibliographique pour le domaine irano-aryen

Volume 40-41 | 2019

Comptes rendus des publications de 2017-2018
\end{abstract}

\title{
Philip Wood, « Constantine in the Chronicle of Seert »
}

\section{Christelle Jullien}

\section{(2) OpenEdition \\ 12 Journals}

\section{Édition électronique}

URL : http://journals.openedition.org/abstractairanica/50942

DOI : 10.4000/abstractairanica.50942

ISBN : 1961-960X

ISSN : 1961-960X

Éditeur :

CNRS (UMR 7528 Mondes iraniens et indiens), Éditions de l'IFRI

Référence électronique

Christelle Jullien, «Philip Wood, « Constantine in the Chronicle of Seert » », Abstracta Iranica [En ligne], Volume 40-41 | 2019, document 14, mis en ligne le 30 décembre 2019, consulté le 27 avril 2021. URL http://journals.openedition.org/abstractairanica/50942 ; DOI : https://doi.org/10.4000/ abstractairanica. 50942

Ce document a été généré automatiquement le 27 avril 2021

Tous droits réservés 


\title{
Philip Wood, «Constantine in the Chronicle of Seert »
}

\author{
Christelle Jullien
}

\section{RÉFÉRENCE}

Philip Wood, « Constantine in the Chronicle of Seert », Studies in Late Antiquity 1/2, 2017, p. $150-172$

1 L'Histoire syro-orientale dite chronique de Séert est une chronique arabe composée en Irak au Xe ou XI $\mathrm{XI}^{\mathrm{e}}$ siècle à partir de sources antérieures en syriaque aujourd'hui perdues. Il n'en subsiste qu'un manuscrit unique. Elle est d'une importance considérable pour notre connaissance de l'histoire des communautés chrétiennes de l'empire sassanide ; mais seules les années 251 à 423 et 483 à 650 ont été conservées. Dans cet article, l'A., spécialiste des processus de rédaction historique en syriaque et en arabe, et plus spécialement de la dite chronique, analyse la réception de l'histoire de Constantin dans les cercles chrétiens mésopotamiens entre $\mathrm{IX}^{\mathrm{e}}$ et $\mathrm{X}^{\mathrm{e}}$ siècle. Une mise en perspective des échanges interculturels entre la Mésopotamie sassanide et l'empire romain oriental lui permet d'éclairer les relations littéraires entre ces deux régions frontalières. Il souligne que des sources ecclésiastiques produites en contexte romain furent importées en milieu mésopotamien autour du $\mathrm{VI}^{\mathrm{e}}$ siècle et servirent au renforcement identitaire de l'Église de Perse. L'A. souligne par exemple la liberté d'usage de l'héritage d'Eusèbe de Césarée, qui servit pourtant de soubassement à l'écriture historiographique syriaque : la mémoire de l'empereur Constantin et de sa famille est ainsi davantage dominée par l'influence de textes pseudo-historiques comme la Doctrine d'Addaï ou le Roman de Julien l'Apostat, composés en syriaque en milieu édessénien aux $\mathrm{V}^{\mathrm{e}}$ et $\mathrm{VI}^{\mathrm{e}}$ siècles. Précisons que la tendance est actuellement à une datation un plus haute de la rédaction primitive de la Doctrine d'Addaï, à la fin du IV ${ }^{\mathrm{e}}$ siècle, cf. F. Amsler, J.-D. Kaestli, D. Marguerat, Le mystère apocryphe : introduction à une littérature méconnue, Genève, Labor et Fides, 2007, p. 35. Après la conquête arabe, dans un environnement islamisé, la transmission de la figure de Constantin s'est essentiellement transmise à travers sa contribution à 
l'orthodoxisation de la foi chrétienne : d'abord pour son rôle dans l'établissement du credo de Nicée, partagé par toutes les grandes confessions chrétiennes au sein du califat; ensuite son implication dans l'établissement du culte de la Croix, un symbole fort qui divisait chrétiens et musulmans.

\section{AUTEURS}

\section{CHRISTELLE JULLIEN}

CNRS, Mondes iranien et indien, Paris 